Consequently the $2^{10}$ power of 16 , or the $2^{12}$ power of 2 , increased by 1 , is divisible by $7 \times 2^{14}+I$

In the second case, we find the remainders

$\begin{array}{lrrrrrr}r_{3}=-4 & 0 & 0 & 0 & 0 & 1 & 10 \\ r_{4}=-7 & 9 & 9 & 9 & 7 & 0 & 11 \\ r_{5}=-9 & 8 & 2 & 10 & 9 & 9 & 4 \\ r_{6}=-4 & 6 & 6 & 11 & 8 & 8 & 11 \\ r_{7}=-2 & 2 & 3 & 12 & 10 & 8 & 5 \\ r_{8}=-9 & 14 & 1 & 0 & 14 & 6 & 10 \\ r_{9}=-6 & 9 & 14 & 11 & 8 & 11 & 0 \\ r_{10}=-3 & 14 & 4 & 6 & 15 & 1 & 3 \\ r_{11}=-7 & 7 & 10 & 5 & 12 & 10 & 4 \\ r_{12}=-7 & 12 & 1 & 4 & 5 & 1 & 4 \\ r_{13}=-7 & 3 & 7 & 12 & 8 & 1 & 2 \\ r_{14}=-5 & 1 & 13 & 9 & 4 & 6 & 4 \\ r_{15}=-3 & 15 & 2 & 2 & 4 & 13 & 3 \\ r_{16}=-1 & 5 & 6 & 9 & 1 & 2 & 6 \\ r_{17}=-2 & 5 & 9 & 12 & 5 & 9 & 3 \\ r_{18}=-7 & 13 & 11 & 14 & 2 & 8 & 5 \\ r_{19}=-8 & 3 & 0 & 0 & 6 & 15 & 7 \\ r_{20}=-3 & 14 & 3 & 10 & 2 & 11 & 0 \\ r_{21}=- & & & & & & 1\end{array}$

Consequently, the $2^{21}$ power of 16 , or the $2^{23}$ power of 2 , increased by 1 , is divisible by $5 \times 2^{25}+1$.

The work involved in the first verification can be done by a good calculator in less than half-an-hour; the second is, I think, not more than thrice as long, for the divisions are more easily performed.

Here is one of the eighteen stages of the work of the second verification, nainely, the getting of $r_{6}$ from $r_{5}$.

\begin{tabular}{llllllll}
$r_{S}=$ & 9 & 8 & 2 & ro & 9 & 9 & 4 \\
\hline & 9 & & & & & & \\
$\mathbf{x}$ & 2 & 8 & & & & & \\
$\mathbf{x}$ & 3 & 0 & 2 & & & & \\
$\mathbf{x}$ & 3 & 0 & 4 & ro & & & \\
$x$ & 3 & 0 & 5 & 4 & 9 & & \\
$\mathbf{x}$ & 3 & 0 & 5 & 5 & 2 & 9 & \\
$x$ & 3 & 0 & 5 & 5 & 3 & 2 & 4
\end{tabular}

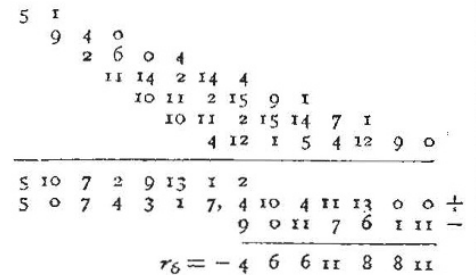

The last four lines of the work are made up thus:-In adding the parts of the square depress the last six places to line 2 , leaving the rest in line $\mathbf{r}$; then proceeding to the extreme left, carry the tens figure, in this case 0 , six places to the right, for subtraction into line 3 , and depress the units figure (5) into line 2. Multiply the just depressed figure (5) by 16 , and add to it what is found (IO) in the place to the right of it in line I (giving 90); again carry the tens figure (9) for subtraction into line 3 , and depress the units figure into line 2 ; repeat the process, moving to the right, until line 1 is exhausted; then the difference between line 3 and the last seven places of line 2 gives line 4 , the result required.

For the sake of safety, before proceeding to calculate $r_{7}$, calculate $r_{6}$ again from the complement of $r_{6}$ with reference to the divisor, in this case from $+\begin{array}{lllllll}7 & \text { I } 3 & 5 & 6 & 6 & \text { I3. If }\end{array}$ the same result is again obtained, you may go on confidently.

Hampstead

JOHN BRIDGE

\section{Vulcan and Bode's Law}

IN the year 1778 -just a hundred years ago-the astronomer Bode published an approximation to a law respecting the plane. tary distances. He took the numbers

$$
\text { o, 3, 6, 12, 24, 48, 96, 192, 384, }
$$

each after the second being double the preceding; to these he added 4 , giving

$4,7,10,16,28,52,100,196,388$,

numbers which, with the exception of the last, agree very well with the distances of the planets from the sun:-

$$
3 \cdot 8,7^{\circ} 2, \text { ro, } 15^{*} 2,(27), 5^{2}, 95^{\circ} 3,191^{\circ} 8,300 \cdot 3 \text {. }
$$

The publication of this law, at a time when the asteroids between Mars and Jupiter were as yet undiscovered, drew attention to Kepler's speculation that a planet was wanting between Mars and Jupiter. Twenty-one years after Ceres, the first of the asteroids, was discovered, and then others, until now there are nearly 200 , the average distance of the whole being 27 and agreeing very well with Bode's number 28 . All this is doubtless known to the majority of your readers.

In calling attention to the law, while not wishing to attach too much importance to it, I would point out one or two suggestions which present themselves. If we place 3 before the o in the first row of figures the line becomes

$$
-3,0,3,6, \mathbf{1 2}, \& \mathrm{c} \text {. }
$$

If 4 be now added the numbers are

$$
\text { I, 4, 7, 10, 16, \&c. }
$$

The number 4 in this line represents the relative distance of Mercury from the sin; may not the number I represent the distance of Vulcan, or more probably the mean distance of a ring of asteroids, of which Vulcan is the brightest?

Referring now to the modified law, represented by the numbers

\section{$1,4,7,10,16,28,52,100,196,388$,}

if $\mathbf{r}$ represents the mean distance of the Vulcan-asteroids, and 28 that of the Ceres-asteroids, it is a fact that after the first ring come four planets, Mercury, Venus, Earth, Mars, and after the second ring four planets, Jupiter, Saturn, Uranus, Neptune, the two sets of planets having marked differences as regards axial rotation and density.

What, then, is beyond Neptune? The law seems to say, a ring of asteroids at an average distance of 772 . The mation of Neptune does not lead astronomers to suspect a planet beyond. Perhaps the optical instruments of the future may help to answer this question, Is there a ring of asteroids beyond Neptune?

4, Buccleuch Road, Dulwich

B. G. JENKINS

\section{Irish Bog Oak}

CAN you or any correspondent kindly give me the scientific name of the Irish "bog-oak" (fossil)? It should be either Quercus pedunculata or $Q$. sessiliflora, the existing species, but though I have seen many specimens, I never got hold of one which would enable me to determine the species, and, for aught

I know, there may be some of both. 46, Guilford Street, W.C.

\section{OUR ASTRONOMICAL COLUMN}

THE TOTAL SOlan EClipse OF JANUARY II, I880The central line in this eclipse ends soon after reaching the coast of California, where it is possible totality may be witnessed close upon sunset. Tracing the previous path of the shadow through its long course across the Pacific with the aid of the Admiralty chart, it will be found that the only islands included within it are the Coquille, Bonham, and Elizabeth Islands, lying near together, between $169^{\circ}$ and $170^{\circ} \mathrm{E}$. longitude, and belonging to the Marshall Islands group. The eclipse passes centrally over the largest of the Coquilles, as laid down in the Admiralty chart of this group, according to a calculation in which the moon's place has been made to accord very nearly with Hansen corrected to Newcomb, which gives the following track:-

$$
\begin{aligned}
& \text { Long. E. Lat. N. limit. Lat. Cent. line. Lat. S. limit. } \\
& 168 \quad \ldots+6446 \quad \ldots+6 \frac{0}{6} 28.0 \quad \ldots+\frac{0}{6} 11 \cdot 6
\end{aligned}
$$

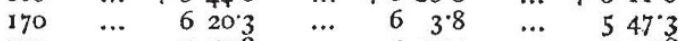

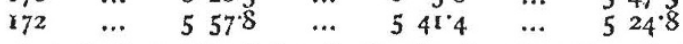

So that the breadth of the shadow in the direction of the meridian does not exceed $33^{\prime}$. " Reading off from the chart, it will be found that the centre of the largest of the Coquille Islands is in about $169^{\circ} 35^{\prime} .5 \mathrm{E}$. and $6^{\circ} 8^{\prime} \cdot 5 \mathrm{~N}$., and, calculating directly for this point, it appears that the total eclipse will commence at $8 \mathrm{~h} .4 \mathrm{Im} .25 \mathrm{~s}$. A.M. on January 12 , local mean time, and continue Im. 16s., and this represents the most favourable condition under which the eclipse can be observed on land. For any other point within the shadow in this vicinity the duration of totality may be determined by the fol- 
lowing formulæ, where $\mathrm{L}$ is the east longitude from Greenwich, $l$ the geocentric latitude, and $t$ the Greenwich mean time of beginning or ending, according as the upper or lower sign is employed :-

Cos. $w=+109^{\circ} 00 x^{1}-\left[2^{\circ} 34^{2} 85\right] \sin . l+\left[x^{\circ} 9^{\circ} 8006\right] \cos . l \cos .\left(L-15^{\circ} \times 5^{\circ} 9\right)$. $t=x$ xh. $x$ om. $4^{8} \cdot 9^{\mathrm{s}}$. 干 $\left[\mathrm{r}^{\circ} 58 \times 54\right] \sin , w+\left[3^{\circ} \mathrm{r}^{6228}\right] \sin . l^{\circ}$.

$$
-\left[395^{668}\right] \cos . l \cdot \cos \left(\mathrm{L}-126^{\circ} 35^{\circ} 7\right) \text {. }
$$

TRANSITS OF MERCURY.-Prof. Holden has published an "Index-Catalogue of Books and Memoirs on the Transits of Mercury," which he had prepared to aid him in a search for records of the physical phenomena which have been observed at such transits. The list is not quite a complete one, the publications of observatories not being included, but there is little inconvenience in the omission, as such observations and memoirs can be found by reference to the volumes for transit years, and Prof. Holden gives a list of the dates of all the transits of Mercury so far observed. Catalogues of this description must prove most serviceable to the student and to every one who has occasion to consult the general literature of an astronomical subject, and we hope the American astronomer may find leisure to continue them. Reference has already been made in this column to his very valuable "Index-Catalogue to the Literature of Nebulæ and Clusters," \&c., forming No. 3II of the "Smithsonian Miscellaneous Collections." The publication above men. tioned forms No. I of "Biographical Contributions," edited by Justin Winsor, Librarian of Harvard University. The copy before us is republished from the Bulletin of the library for October, 1878 .

BIELA'S COMET AND JUPYTER IN I794.- It will be remembered by those who may have interested themselves in cometary astronomy, that between the first appearance of Biela's comet in 1772, and the next return at which it was observed, in the latter part of 1805 , the elements had undergone alterations of a magnitude that occasioned doubts as to the identity of the comets, notwithstanding the general similarity of orbits, Bessel pronouncing against it, while Gauss pointed out that more than one revolution must have been accomplished in the interval, so as to admit of the comet having approached one of the larger planets and thereby experienced perturbation to account for the differences in several of the elements. The disturbing body is now known to have been the planet. Jupiter, and there bas been no difficulty in fixing the epoch when the comet's motion was most deflected, but we do not recollect to have seen the particulars of the near approach of the two bodies stated in any astronomical work. Starting from the final elements for perihelion passage in 1806 , determined in the masterly investigation of the late Prof. Hubbard of Washington, it appears that neglecting planetary perturbation in the interval, the comet would have made its nearest approach to the planet at the beginning of June, 1794, when their distance was less than 0477 of the mean distance of the earth from the sun. The following distances have been similarly obtained:-

\begin{tabular}{|c|c|c|c|c|c|c|c|c|c|}
\hline 3794 & & & & $\begin{array}{l}\text { Distance } \\
\text { from } \\
\text { Jup.ter. }\end{array}$ & \multicolumn{2}{|c|}{5794} & & & $\begin{array}{l}\text { Distance } \\
\text { from } \\
\text { Jupiter. }\end{array}$ \\
\hline March & & & & 0.654 & May & $3 \mathbf{I}$ & $\cdots$ & $\cdots$ & 0.469 \\
\hline April & I & $\ldots$ & $\ldots$ & 0.562 & June & 15 & $\ldots$ & $\ldots$ & 0.473 \\
\hline May & 1 & $\cdots$ & $\cdots$ & 0.496 & ", & 30 & $\ldots$ & $\ldots$ & 0.488 \\
\hline$"$ & & $\cdots$ & $\ldots$ & 0.477 & & & & & \\
\hline
\end{tabular}

At the time of closest approximation, the heliocentric longitude of the comet was about $269^{\circ} 40^{\prime}$, and the latitude $+4^{\circ} 25^{\prime}$.

\section{BIOLOGICAL NOTES}

GaLl-MAKING InSECTS.-At the St. Louis meeting of the American Association Prof. C. V. Riley read a paper on the gall-making Pemphigina. He said that the life-history and agamic multiplication of the plant-lice (Aphidida) have always excited the interest of entomologists as well as of anatomists and embryologists. The life-history, however, of the gallmaking species belonging to the Pemphigince has baffled the skill of observers more than that of any other group. Mr. Riley is about to publish some new biological discoveries relating to this family of insects, in connection with a descriptive and monographic paper by $\mathrm{Mr}$. J. Monell, of the St. Louis Botanic Gardens. The paper laid before the Association simply records some of the yet unpublished facts discovered. All of the older writers, in treating of the different gall-producing Pemphigince of Europe, have invariably failed to trace the life-history of the different species after the winged females leave the galls, and, with few exceptions, have erroneously inferred that the direct issue from the winged females hibernates somewhere. The most recent production on the subject is a paper published in the present year in Cassel, by Dr. H. F. Kessler, which is entitled the "Life-History of the Gall-Making Plant-Lice, affecting Ulmus campestris." The author, by a series of ingenious experiments, rightly came to the conclusion that the insects hibernate on the trunk, but he failed to discover in what condition they so hibernate. Led by his previous investigations into the habits of the grape Phylloxera, Mr. Riley discovered, in 1872 , that some of our elm-feeding species of Pemphigina produce wingless and moutbless males and females, and that the female lays but one solitary impregnated egg. Continuing his observations, especially during the present summer, he has been able to trace the life-history of those species producing galls on our own elms, and to show that they all agree in this respect, and that the impregnated egg produced by the female is consigned to the sheltered portions of the trunk of the tree and there hibernatesthe issue therefrom being the stem-mother which founds the gall-inhabiting colony the ensuing spring. Thus the analogy in the life-history of the Pemphigine and the Phylloxerince is established, and the question as to what becomes of the winged insects after they leave the galls is no longer an open one. They instinctively seek the bark of the tree and there give birth to the sexual individuals, either directly or (in one species) through intervening generations.

LEAF ABsorption IN Plants.-The earlier experimenters on this subject, M. Perault, to wit, and Hales (173I), were persuaded that leaves absorbed dew and rain. For over a century the investigations of others supported this view, until M. Duchartre, in 1857 , from his experiments, advanced a contrary opinion - that now held by most vegetable physiologists, and commonly taught in our schools. But, strange to say, gardeners, in their every-day operations, adopt a different notion from that prevailing in science. The subject has recently received the attention of the Rev. G. Henslow, who, in a paper read before the Linnean Society (November 7), shows that, while it may be true that, as Duchartre has said, dew is not absorbed by saturated tissues at night; yet, on the contrary, his (Henslow's) experiments go to prove that absorption does take place at and after sunrise, when transpiration recommences, and an indraught is caused by the moisture, wherever lingering on the leaves. He further corroborates M. Boussingault's late assertion, that, when leaves are purposely or naturally killed by excessive drought, they then do absorb water, as proved by the balance, or otherwise.

BRITish NewTS.-From an article by M. Ferrand Lataste in the last vclume of the Journal of the Société Zoologique de France, it appears that the supposed fourth species of British newt-Gray's banded newt (Ommatotriton vittatus) of Mr. Cooke's "Our Reptiles"-may be altogether removed from the British catalogue. It was first introduced into the British list by Jenyns, in 1835 , on the faith of some specimens found in a bottle in the 